\title{
Salt-Resistant Switchable Pickering Emulsions Stabilized by \\ Mesoporous Nano-silica Hydrophobized In Situ by pH-insensitive
}

\section{Surfactants}

Danhua Xie,,${ }^{\mathrm{a},}$ Yulong Jiang, ${ }^{\mathrm{a}}$ Y unjin Zhang, ${ }^{\mathrm{a}, \mathrm{c}}$ and Binglei Song ${ }^{\mathrm{b}}$

a Fujian Provincial Key Laboratory of Featured Materials in Biochemical Industry, College of Chemistry and Materials, Ningde Normal University, Ningde, Fujian 352100, China.

E-mail: danhuaxie@ndnu.edu.cn

b Key Laboratory of Synthetic and Biological Colloids, Ministry of Education, School of Chemical \& Materials Engineering, Jiangnan University, Wuxi, Jiangsu 214122, China.

c College of Chemistry, Fuzhou University, Fuzhou, Fujian 350002, China.

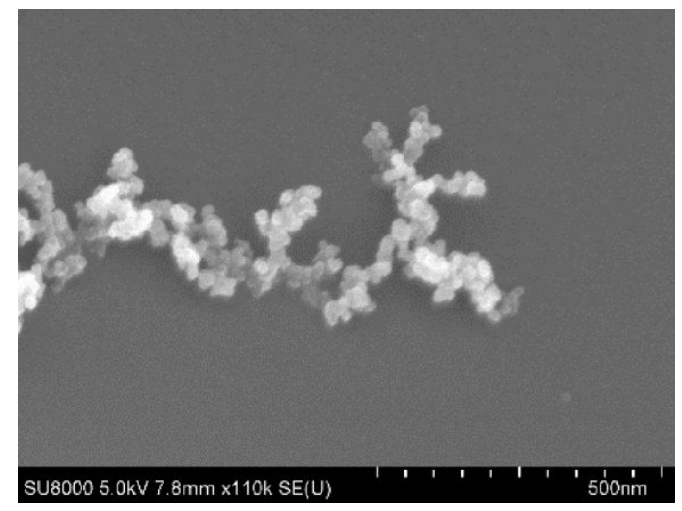

Figure S1 The SEM image of silica nanoparticles
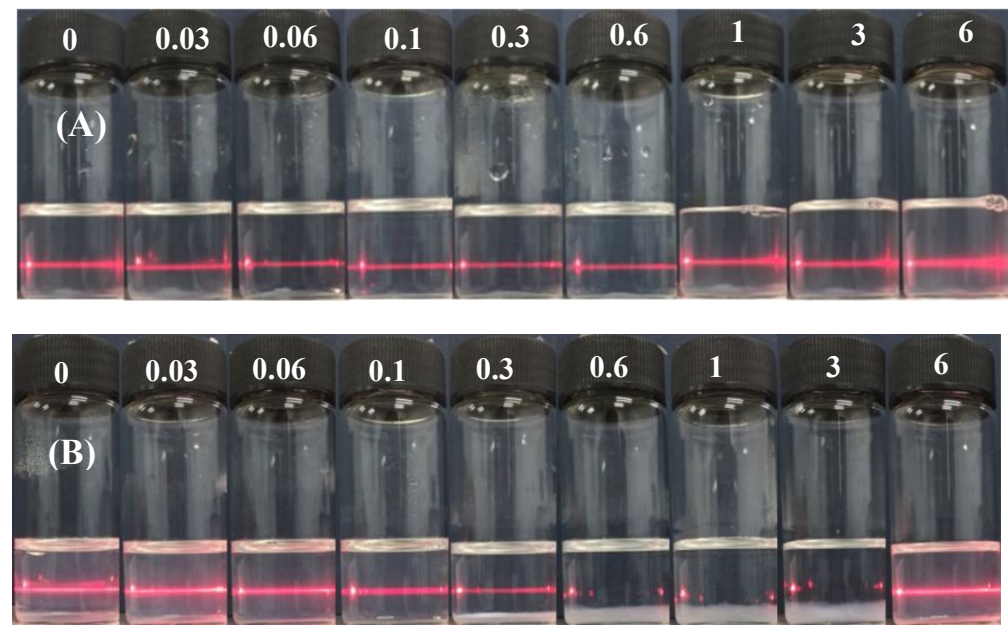

Figure S2 Digital photographs of $0.1 \mathrm{wt} \%$ (A) mesoporous silica nanoparticles or (B) common silica nanoparticles dispersed in CTAB aqueous solutions at various concentrations $\left(\mathrm{mmol} \cdot \mathrm{L}^{-1}\right)$. 


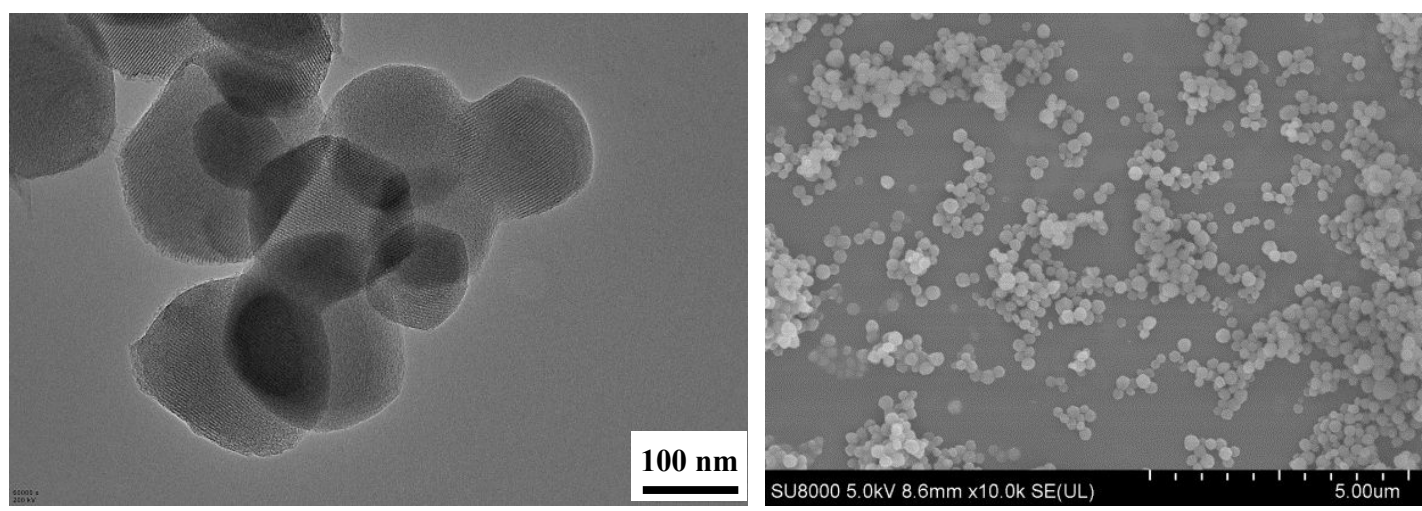

Figure S3 TEM (left) and SEM (right) images of mesoporous silica nanoparticles
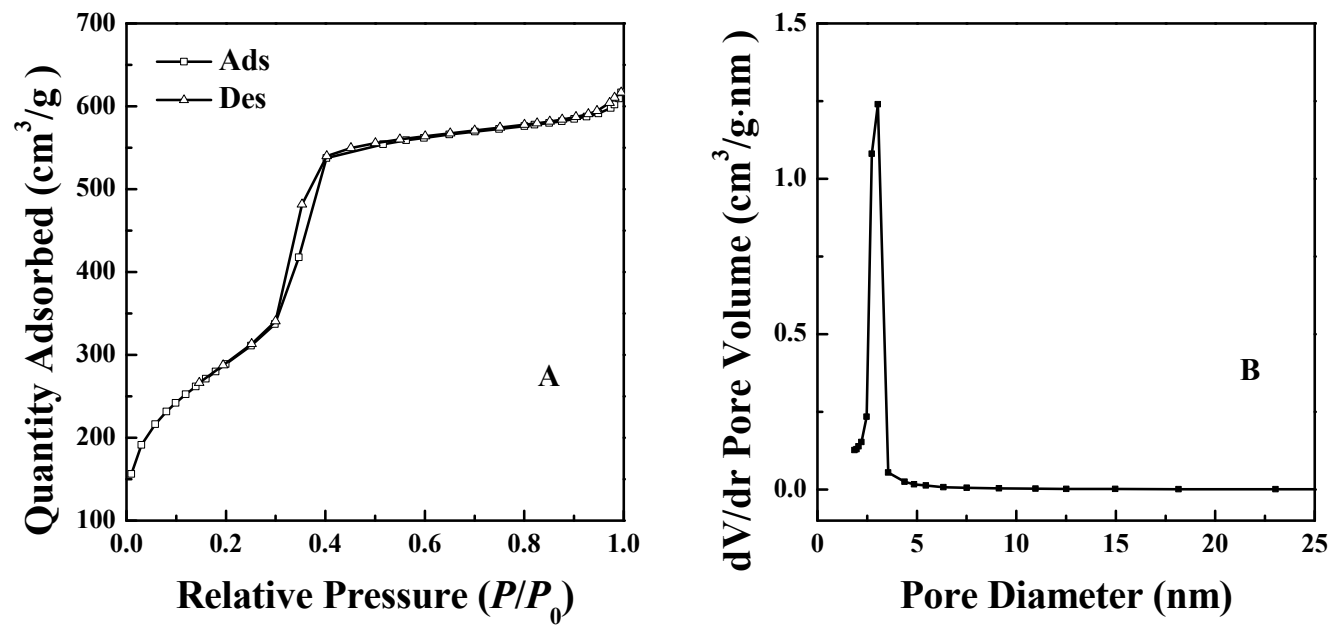

Figure $\mathbf{S 4} \mathrm{N}_{2}$ adsorption-desorption isotherms (A) and BJH pore size distributions (B) of mesoporous silica nanoparticles

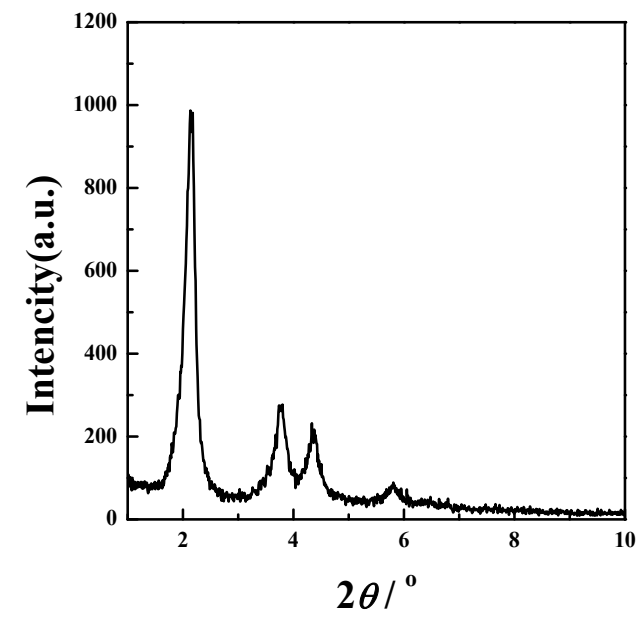

Figure S5 Small-angle XRD patterns of mesoporous silica nanoparticles 
Table S1 Characteristics of spherical mesoporous silica nanoparticles

\begin{tabular}{cccc}
\hline $\begin{array}{c}\text { Size by TEM } \\
(\mathrm{nm})\end{array}$ & $\begin{array}{c}\text { Surface area } \\
S_{\mathrm{BET}}\left(\mathrm{m}^{2} \cdot \mathrm{g}^{-1}\right)\end{array}$ & $\begin{array}{c}\text { Pore volume } \\
V\left(\mathrm{~cm}^{3} \cdot \mathrm{g}^{-1}\right)\end{array}$ & $\begin{array}{c}\text { Pore size } \\
D_{\mathrm{p}}(\mathrm{nm})\end{array}$ \\
\hline$\sim 150$ & 1055 & 0.92 & 3.08 \\
\hline
\end{tabular}

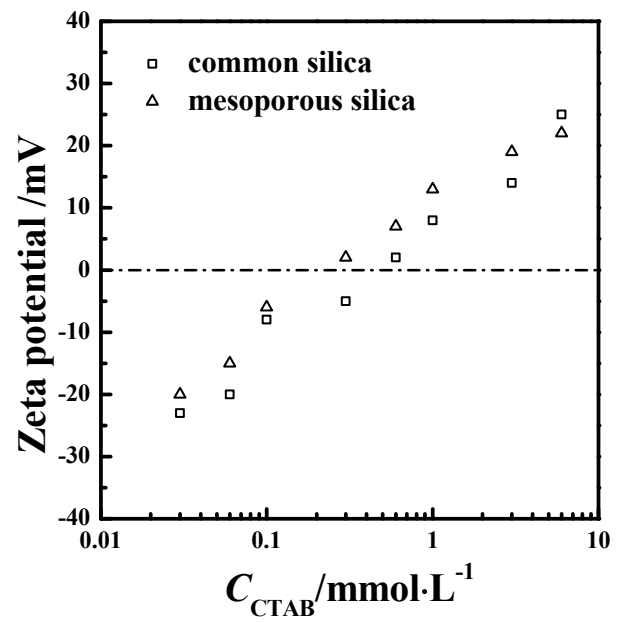

Figure S6 Zeta potentials of $0.1 \mathrm{wt} \%$ mesoporous silica nanoparticles and common silica nanoparticles dispersed in aqueous solutions of various concentrations of CTAB.

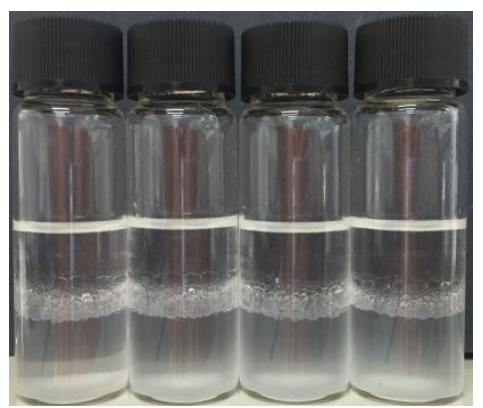

Figure S7 Digital photographs of Pickering emulsions stabilized by mesoporous silica nanoparticles with concentration of $0.1 \mathrm{wt} \%, 0.3 \mathrm{wt} \%, 0.5 \mathrm{wt} \%$, and $1 \mathrm{wt} \%$, from left to right, taken $1 \mathrm{~h}$ after preparation.
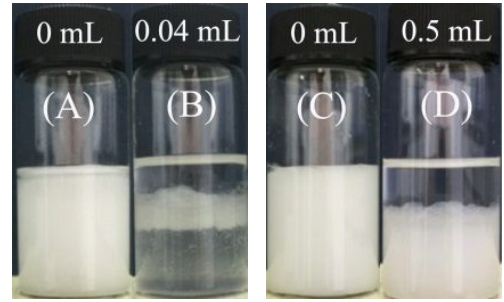

Figure S8 Digital photographs of Pickering emulsion stabilized by $0.3 \mathrm{wt} \%$ mesoporous silica in combination with CTAB at concentrations of (A-B) $2 \mathrm{mmol} \cdot \mathrm{L}^{-1}$ and (C-D) $10 \mathrm{mmol} \cdot \mathrm{L}^{-1}$, and (B, D) demulsified by following addition of the indicated volume of $1 \mathrm{~mol} \cdot \mathrm{L}^{-1} \mathrm{NaOH}$, taken $10 \mathrm{~s}$ after the addition of $\mathrm{NaOH}$. 

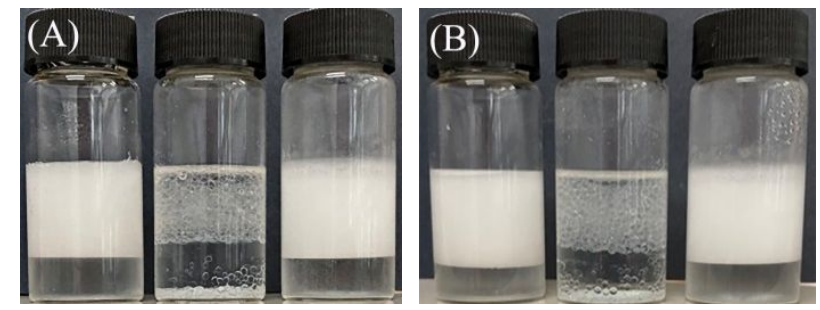

Figure S9 Digital photographs of Pickering emulsion first stabilized by $0.3 \mathrm{wt} \%$ mesoporous silica nanoparticles in combination with $0.3 \mathrm{mmol} \cdot \mathrm{L}^{-1}$ cationic surfactants (A) DTAB and (B) $\mathrm{TTAB}$, and then switched between unstable and stable states by alternately adding $\mathrm{NaOH}$ and then an equimolar amount of $\mathrm{HCl}$. Photographs were taken $10 \mathrm{~s}$ after the addition of $\mathrm{NaOH}$ and $24 \mathrm{~h}$ after the addition of $\mathrm{HCl}$, respectively.
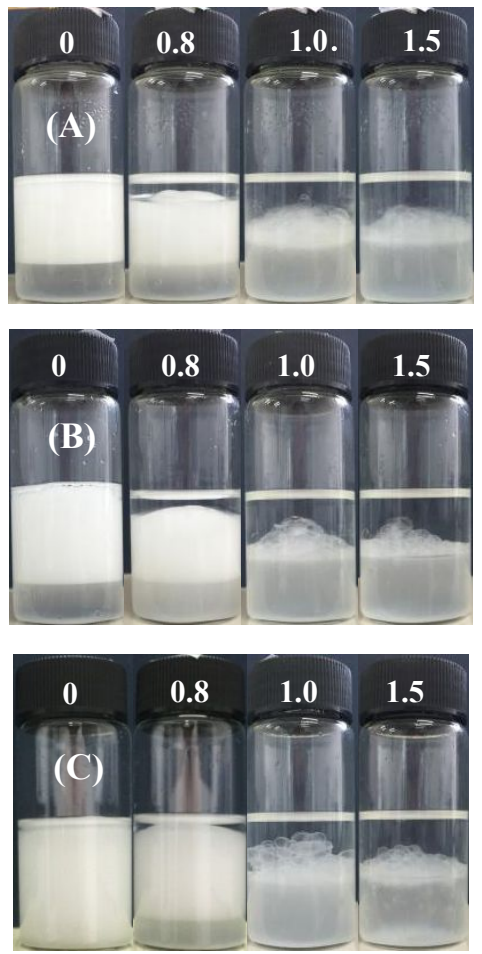

Figure S10 Digital photographs of demulsification of Pickering emulsions stabilized by $0.3 \mathrm{wt} \%$ mesoporous silica in combination with $\mathrm{CTAB}$ at concentrations of (A) $0.3 \mathrm{mmol} \cdot \mathrm{L}^{-1}$, (B) 0.6 $\mathrm{mmol} \cdot \mathrm{L}^{-1}$, and (C) $2 \mathrm{mmol} \cdot \mathrm{L}^{-1}$ after additions of $\mathrm{NaOH}$. The mole ratios of $\mathrm{NaOH}$ to $\mathrm{CTAB}$ are 0 , $0.8,1.0$ and 1.5 , respectively.

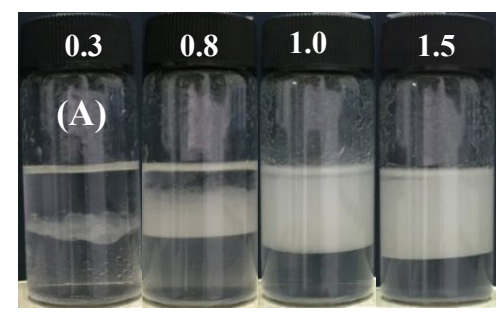



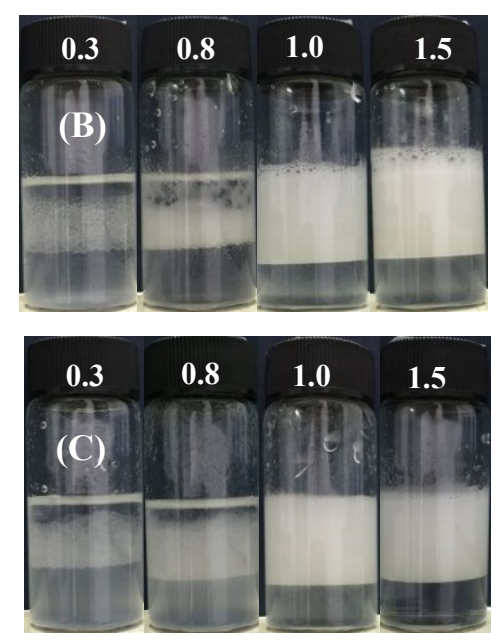

Figure S11 Digital photographs of Pickering emulsions re-emulsified after addition of $\mathrm{HCl}$ to the demulsified systems by $\mathrm{NaOH}$. The mole ratios of $\mathrm{HCl}$ to $\mathrm{NaOH}$ are $0.3,0.8,1.0$ and 1.5, respectively. The concentration of CTAB is (A) $0.3 \mathrm{mmol} \cdot \mathrm{L}^{-1}$, (B) $0.6 \mathrm{mmol} \cdot \mathrm{L}^{-1}$, and (C) 2 $\mathrm{mmol} \cdot \mathrm{L}^{-1}$.

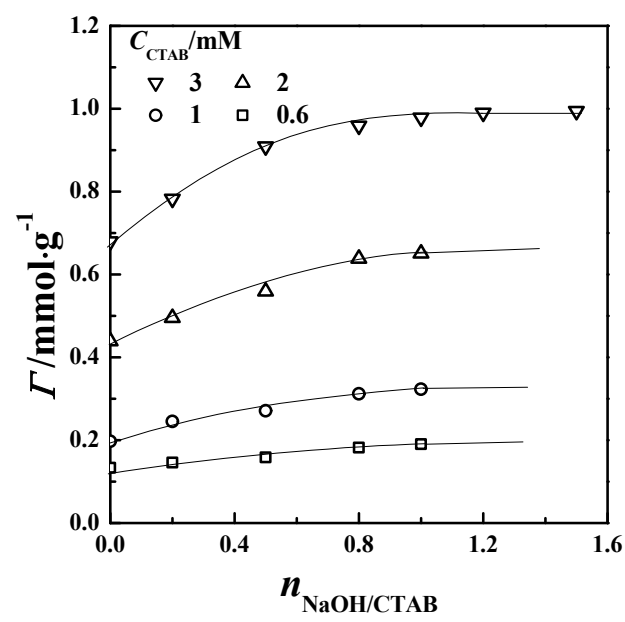

Figure S12 Adsorption of CTAB on mesoporous silica nanoparticles at different mole ratio of $\mathrm{NaOH}$ to $\mathrm{CTAB}\left(25^{\circ} \mathrm{C}\right)$ 